\title{
The effect of hydroalcoholic extract of Teucrium polium $L$. on the inflammatory markers and lipid profile in hypercholesterolemic rats
}

This article was published in the following Dove Press journal: Journal of Inflammation Research

\author{
Mansour Amraei ${ }^{1, *}$ \\ Ayub Ghorbani',* \\ Yaser Seifinejad' \\ Seyedeh Fatemeh Mousavi ${ }^{2}$ \\ Mahmoud Mohamadpour ${ }^{3}$ \\ Ehsan Shirzadpour ${ }^{3}$ \\ 'Department of Physiology, Faculty of \\ Medicine, Ilam University of Medical \\ Sciences, Ilam, Iran; ${ }^{2}$ Student Research \\ Committee, Ilam University of Medical \\ Sciences, Ilam, Iran; ${ }^{3}$ Department of \\ Biochemistry, Faculty of Medicine, \\ Ilam University of Medical Sciences, \\ Ilam, Iran \\ *These authors contributed equally to \\ this work
}

Background: Cardiovascular diseases are among the most common causes of mortality worldwide. Therefore, it is necessary to control the risk factors of these patients. Since the level of inflammatory markers and lipid profiles has increased in cardiovascular diseases and due to the increasing role of plants in the treatment of diseases, the current study aimed to investigate the effect of hydroalcoholic extract of Teucrium polium on inflammatory markers and lipid profile in hypercholesterolemic rats.

Materials and methods: A total of 24 adult male Wistar rats were randomly divided into four groups of six each and treated with oral administration for 8 weeks. The control group received normal diet, the sham group received high-cholesterol diet and experimental groups 1 and 2 received high-cholesterol diet in the 8 weeks and doses of 85 and $170 \mathrm{mg} / \mathrm{kg}$, respectively, of the T. polium hydroalcoholic extract (TPHAE) in the second 4 weeks. At the beginning and the end of the study, rats were examined for biochemical parameters. The mean level of variables for each group was presented as mean \pm standard error of mean.

Results: The results of this study showed that, after administration of TPHAE, there was a significant decrease in the mean of inflammatory markers in all groups compared to sham group $(P<0.001)$. Also, administration of the extract significantly reduced the serum levels of triglyceride, cholesterol and LDL-cholesterol and significantly increased the serum HDL-cholesterol levels. In addition, the $170 \mathrm{mg} / \mathrm{kg}$ dose of TPHAE was the most effective in reducing serum levels of inflammatory and lipid markers.

Conclusion: Treatment with TPHAE caused dose-dependent decrease in serum levels of inflammatory markers and lipid profile in hypercholesterolemic rats. Therefore, it can be applied as a natural product for the management of cardiovascular diseases.

Keywords: Teucrium polium, inflammatory markers, lipid profile, male rat

\section{Introduction}

Cardiovascular diseases are among the important global health problems and the most common causes of death worldwide, posing severe physical and economic losses not only to individuals but also to the entire community. ${ }^{1,2}$ Atherosclerosis is the leading cause of cardiovascular diseases, which causes hardening of the arterial wall, followed by a decrease in elasticity and a narrowing of the blood flow pathway and ultimately a decrease in the blood flow of the vital organs of the body, including the heart and brain. ${ }^{3}$

Immune inflammation has now been known in the pathogenesis of atherosclerosis; inflammation is created with increasing oxidative stress, followed by events such as plaque rupture and, consequently, vascular arterial disorder. ${ }^{3}$ At the initial stage of atherosclerosis, cholesterol-rich lipoproteins are stored in the vessel wall and cause
Correspondence: Ehsan Shirzadpour Department of Biochemistry, Faculty of Medicine, Ilam University of Medical Sciences, Ilam 6939177/43, Iran

Tel +98 8432235745

Fax +988432235723

Email ehsan.shp66@yahoo.com 
inflammatory responses in the surrounding cells; as a part of this vascular response, arterial endothelial cells express leukocytic adhesion molecules that leads to the attraction of circulating monocytes, their adherence to endothelium and differentiation into tissue macrophages. ${ }^{4-6}$ These macrophages absorb lipids and create foam cells in blood vessels, with the first lesions being atherosclerotic processes, and play a very important role in the development and progress of atherosclerosis. ${ }^{7}$

Nowadays, with the changing pattern of life along with the industrialization of societies and the changes in food habits and reduced physical activity, the incidence of cardiovascular disease, especially in developing countries, has been steadily increasing. ${ }^{8}$ Clinical and epidemiological evidence suggests a significant reduction in cardiovascular mortality among consumers of fruits, vegetables and materials extracted from plants due to the presence of polyphenolic compounds and their special flavonoids. ${ }^{9,10}$ Because of their antioxidant activity, flavonoids protect the destructive effects of reactive oxygen species, such as superoxide radicals. ${ }^{11}$ Owing to the role of flavonoids in the treatment of cardiovascular diseases, it is necessary to use plants that have beneficial effects for these diseases. One of such herbs is Teucrium polium.

T. polium from Teucrium class is an herbaceous, grassy, branchy, 10-35 cm height, white cotton plant, which is usually found in the Bayer, rocky and sandy beaches worldwide. ${ }^{12}$ In recent years, the antidiabetic, analgesic and antioxidant effects of this plant have been reported. ${ }^{12-15}$ The use of T. polium in vitro reduces fatty acids. It is also used as peroxidation inhibitor of red blood cells. ${ }^{16}$

Considering that cardiovascular diseases are among the most important causes of mortality, implementation of applicable research is necessary in order to recognize and reduce the risk factors of this disease. Meanwhile, investigation and identification of the effective factors on decreasing the level of inflammatory markers and lipid profiles is important for prevention and reduction of cardiovascular diseases. In this regard, due to the significant expansion of herbal medicine, it is essential to investigate and conduct research in this regard. Therefore, this study was conducted to investigate the effect of hydrolytic extract of T. polium on the level of some inflammatory and coagulant markers in hypercholesterolemic rats.

\section{Materials and methods \\ Extract preparation}

In this study, a condensed extract of $T$. polium was used, which was collected in spring from the Romshagan area in west Lorestan province and was dried and powdered by electric mill after identification and confirmation of scientific name. The $50 \mathrm{~g}$ of powder obtained was accurately weighed by a digital balance and was poured into an Erlenmeyer flask. Then, $320 \mathrm{~mL}$ of $96 \%$ ethanol and $80 \mathrm{~mL}$ of distilled water were added and incubated in a shaker incubator at $34^{\circ} \mathrm{C}$ and $140 \mathrm{rpm}$ for 72 hours. The obtained solution was filtered with Whatman filter paper 1 in a rotary machine and ethanol was separated using the vacuum pump, so that solution was concentrated to one-third of the initial volume. Concentration of solution was then carried out for 5 days. The solution obtained from the last stage was sterilized in a flask and stored at $4^{\circ} \mathrm{C}$.

\section{Toxicity determination $\left(\mathrm{LD}_{50}\right)$}

Doses of 50, 100, 200, 400, 800 and $1600 \mathrm{mg} / \mathrm{kg}$ of T.polium hydroalcoholic extract (TPHAE) were selected and injected intraperitoneally into six groups of animals. The mortality rate was measured after 24 hours, while the $\mathrm{LD}_{50}$ was estimated using computer techniques. Then, 25 and $50 \% \mathrm{LD}_{50}$ were selected as the doses to be used in this study ( 85 and $170 \mathrm{mg} / \mathrm{kg}$ body weight per day).

\section{Grouping and treatment of animals}

For this experimental study, adult male Wistar rats with an average weight of $180 \pm 20 \mathrm{~g}$ were used. Animals were purchased from the Animal Breeding Laboratory Center of Tehran Institute of Pasteur. Animals were stored in polycarbonate cages at $12 \pm 2{ }^{\circ} \mathrm{C}$ in 12 cycles of light and darkness and fed with special compressed food and water from Urban Plumbing. All the animals were placed under these conditions 1 week prior to the beginning of the study in order to adapt to the laboratory environment.

In order to implement this study, 24 adult male rats were randomly divided into four groups of six and orally administered food for 8 weeks.

1. Group I (control) received only the daily diet in the 8 weeks.

2. Group II (sham) received high-cholesterol diet $(2 \%)$ in the 8 weeks.

To establish the same condition during experiments both experimental group 1 and 2 were treated with 2 cc solvent medication.

1. Group III (experimental 1) received a high-cholesterol diet $(2 \%)$ in the 8 weeks and a dose of $85 \mathrm{mg} / \mathrm{kg}$ of TPHAE from the fourth week. 
2. Group IV (experimental 2) received a high-cholesterol diet $(2 \%)$ in the 8 weeks and a dose of $170 \mathrm{mg} / \mathrm{kg}$ of TPHAE from the fourth week.

For preparation of a high-cholesterol diet, cholesterol was procured from German Merck Company and the rats were given this highly concentrated cholesterol on daily basis at $2 \%$ of their body weight.

\section{Measuring biochemical factors}

Animals were fasted for 12 hours prior to the beginning of the diet and after the completion of the study and then blood samples were collected from all rats twice, once at the beginning of the first week and again at the end of the eighth week. The collected blood samples were allowed to stand for 40 minutes at laboratory temperature to enable clotting and then centrifuged for serum separation at $2500 \mathrm{rpm}$ for 10 minutes. After serum collection, the rate of inflammatory markers (IL-6, CRP, tumor necrosis factor- $\alpha$ [TNF- $\alpha]$ and fibrinogen) and lipid profiles (HDL, LDL, triglyceride [TG] and cholesterol) were measured for each rat by biochemical kits.

Total cholesterol, TG, LDL-cholesterol (LDL-c) and HDL-cholesterol (HDL-c) were measured using a biochemical enzyme kit and measured by Hitachi's Automatic Analyzer 902. ZellBio Kit (Ulm, Germany) was used to measure IL-6, CRP and Fibrinogen, and Diaclone kit (Besançon, France) and ELISA method were used for evaluation of $\mathrm{GmbH}$ and TNF- $\alpha$.

\section{Statistical analysis}

Statistical analysis was conducted using SPSS16 software (SPSS Inc., Chicago, IL, USA). The average level of variables for each group of rats was presented as mean \pm standard error of mean. To compare the mean of quantitative variables before and after the intervention, paired samples $t$-test was used, and one-way analysis of variance and the Tukey's auxiliary tests were used (the true difference test, termed HSD) for comparing the mean of the groups. The significance level for all tests was considered as $P<0.05$.

\section{Ethical statement}

This study was carried out in accordance with the recommendations of International Council for Laboratory Animal Science. The protocol was approved by the Ethics Committee of Ilam University of Medical Sciences.

\section{Results}

Table 1 shows the mean of inflammatory factors before and after study in control, sham and experimental 1 and 2 groups; however, as it can be seen, before the study, the mean of each inflammatory factor in all groups was approximately the same and there was no significant difference between the studied groups $(P>0.05)$.

Comparison of the mean inflammatory factors in each group before and after the intervention showed that at the end of the eighth week of study, the mean of each inflammatory factor in the control group receiving only the daily diet and also experimental group 2 (2\% high-cholesterol diet and 170 $\mathrm{mg} / \mathrm{kg}$ dose of TPHAE) did not change significantly $(P>0.05)$. While in the sham group receiving a high-cholesterol diet ( $2 \%)$, as well as experimental group 1 ( $2 \%$ high-cholesterol diet and $85 \mathrm{mg} / \mathrm{kg}$ dose of TPHAE), there was a significant increase in the mean of each inflammatory factor at the end of the eighth week of study (Table 1).

The mean serum lipid profiles of control, sham and experimental 1 and 2 groups before and after the study are

Table I Comparison of the mean inflammatory factors in the studied groups before and after the intervention.

\begin{tabular}{|c|c|c|c|c|c|}
\hline Inflammatory factors & & Control group & Sham group & Experimental group I & Experimental group 2 \\
\hline \multirow[t]{3}{*}{ IL-6 } & Before the intervention & $2.82 \pm 0.03$ & $2.83 \pm 0.03$ & $2.84 \pm 0.03$ & $2.85 \pm 0.02$ \\
\hline & After the intervention & $2.83 \pm 0.02$ & $3.85 \pm 0.06$ & $3.29 \pm 0.08$ & $3.01 \pm 0.07$ \\
\hline & $P$-value & 0.745 & 0.000 & 0.009 & 0.065 \\
\hline \multirow[t]{3}{*}{ TNF- $\alpha$} & Before the intervention & $10.84 \pm 0.23$ & $10.88 \pm 0.23$ & $\mathrm{II} .04 \pm 0.22$ & $10.90 \pm 0.18$ \\
\hline & After the intervention & $11.08 \pm 0.18$ & $16.20 \pm 0.19$ & $12.66 \pm 0.14$ & $\mathrm{II} .04 \pm 0.20$ \\
\hline & $P$-value & 0.186 & 0.000 & 0.000 & 0.52 \\
\hline \multirow[t]{3}{*}{ CRP } & Before the intervention & $1.77 \pm 0.06$ & $1.81 \pm 0.06$ & $1.72 \pm 0.06$ & $1.69 \pm 0.07$ \\
\hline & After the intervention & $1.78 \pm 0.06$ & $2.98 \pm 0.07$ & $2.06 \pm 0.08$ & $1.81 \pm 0.11$ \\
\hline & $P$-value & 0.423 & 0.000 & 0.038 & 0.082 \\
\hline \multirow[t]{3}{*}{ Fibrinogen } & Before the intervention & $2.14 \pm 0.09$ & $2.22 \pm 0.06$ & $2.16 \pm 0.08$ & $2.18 \pm 0.58$ \\
\hline & After the intervention & $2.16 \pm 0.05$ & $3.92 \pm 0.06$ & $2.84 \pm 0.10$ & $2.34 \pm 0.10$ \\
\hline & $P$-value & 0.749 & 0.000 & 0.001 & 0.078 \\
\hline
\end{tabular}

Notes: Data were presented based on mean \pm SD. Meaningful statistical significance was calculated using independent $t$-test. Abbreviation: TNF- $\alpha$, tumor necrosis factor- $\alpha$. 
presented in Table 2. The mean of lipid profiles before the study in all groups was approximately the same and no significant difference existed in this case $(P>0.05)$. As observed in Table 2, the mean serum levels of TG, cholesterol and LDL-c in the sham group receiving cholesterol diet $(2 \%)$, as well as experimental group 1 (2\% high-cholesterol diet and $85 \mathrm{mg} / \mathrm{kg}$ dose of TPHAE) significantly increased from the start to the end of study (sham group: TG: $P<0.01$, cholesterol and LDL-c: $P<0.001$; experimental group 1: TG: $P<0.001$, cholesterol and LDL-c: $P<0.01)$. However, there was no significant change in the serum levels of these three factors from the beginning to the end of the study in the control group with normal diet and in experimental group 2 treated with pre-cholesterol diet at a dose of $170 \mathrm{mg} / \mathrm{kg}$ TPHAE $(P>0.05)$. Also, there was a decrease in serum HDL-c levels in both sham and experimental groups 1, compared to the beginning of the study, while the level decreased in the sham group from $33.82 \mathrm{mg} / \mathrm{dL}$ at the beginning of the study to $21.56 \mathrm{mg} / \mathrm{dL}$ at the end of the study $(P<0.001)$, and in experimental group 1 it decreased from $35.06 \mathrm{mg} / \mathrm{dL}$ at the beginning of the study to $24.50 \mathrm{mg} / \mathrm{dL}$ at the end of the study $(P<0.01)$. However, there were no significant changes in serum HDL-c levels in the control and two experimental groups compared to the beginning of the study (Table 2).

After the intervention and at the end of the eighth week, the mean lipid profile and lipid profiles were compared between the groups (Figures 1 and 2); the results indicated that at the end of the eighth week, the mean lipid profile of control and experimental group 2 had a significant decrease compared to the sham group $(P<0.001)$. This decrease was also observed in experimental group 2 compared to experimental group $1(P<0.001)$. Also, in experimental group 1 , the mean concentration of TG and cholesterol had a significant decrease compared to the sham group $(P<0.05$ and $P<0.001$, respectively). The mean HDL-c of the control group and experimental group 2 had a significant increase compared to the sham group $(P<0.001)$. Also, in experimental group 1 , the mean concentration of cholesterol, TG and LDL-c had a significant increase, and mean HDL-c had a significant decrease compared to the control group $(P<0.001)$ (Figure 1).

At the end of the eighth week, the mean of inflammatory factors was significantly lower in all groups than in the sham group $(P<0.001)$. This decrease was also observed in experimental group 2 in the inflammatory indices of fibrinogen, TNF- $\alpha(P<0.001)$ and IL-6 $(P<0.05)$ compared to experimental group 1. The level of all inflammatory indices except CRP in experimental group 1 had a significant increase compared to the control group $(P<0.001)$ (Figure 2).

\section{Discussion}

As mentioned earlier, despite the use of multiple preventive measures cardiovascular diseases are still one of the most common causes of mortality in most societies leading to millions of mortalities annually due to complications from diseases such as heart attack, angina pectoris and heart stroke. ${ }^{4,6}$ In many studies, hyperlipidemia has been identified as an important risk factor for atherosclerosis and cardiovascular disease, and its role in the development of such diseases has been proven. ${ }^{17,18}$ Therefore, the control and treatment of hyperlipidemia can be an important step toward reducing cardiovascular disease.

From the results of this study it was found that there was a significant increase in the levels of serum TG, cholesterol and LDL-c after administration of high-cholesterol diet, while serum HDL-c levels significantly decreased. Administration of hydroalcoholic extract of T. polium significantly

Table 2 Comparison of the mean lipid profile in the studied groups before and after the intervention.

\begin{tabular}{|c|c|c|c|c|c|}
\hline Lipid profile & & Control group & Sham group & Experimental group I & Experimental group 2 \\
\hline \multirow[t]{3}{*}{ TG } & Before the intervention & $70.10 \pm 2.48$ & $68.34 \pm 2.49$ & $66.58 \pm 1.85$ & $67.64 \pm 2.87$ \\
\hline & After the intervention & $71.32 \pm 2.11$ & $114.58 \pm 2.90$ & $102.06 \pm 2.39$ & $75.92 \pm 2.96$ \\
\hline & $P$-value & 0.274 & 0.01 & 0.001 & 0.055 \\
\hline \multirow[t]{3}{*}{ Cholesterol } & Before the intervention & $82.32 \pm 2.77$ & $82.46 \pm 2.14$ & $81.28 \pm 1.80$ & $83.81 \pm 2.00$ \\
\hline & After the intervention & $84.38 \pm 2.59$ & $141.22 \pm 3.27$ & $108.09 \pm 3.97$ & $87.18 \pm 2.80$ \\
\hline & $P$-value & 0.210 & 0.001 & 0.01 & 0.367 \\
\hline \multirow[t]{3}{*}{ LDL-c } & Before the intervention & $45.38 \pm 1.59$ & $45.60 \pm 1.38$ & $43.42 \pm 1.75$ & $48.58 \pm 0.92$ \\
\hline & After the intervention & $46.30 \pm 1.29$ & $76.02 \pm 2.33$ & $70.18 \pm 2.45$ & $48.56 \pm 2.10$ \\
\hline & $P$-value & 0.257 & 0.001 & 0.01 & 0.993 \\
\hline \multirow[t]{3}{*}{ HDL-c } & Before the intervention & $34.40 \pm 0.52$ & $33.82 \pm 0.58$ & $35.06 \pm 0.96$ & $35.16 \pm 0.75$ \\
\hline & After the intervention & $35.02 \pm 0.88$ & $21.56 \pm 0.76$ & $24.50 \pm 1.03$ & $32.74 \pm 0.96$ \\
\hline & $P$-value & 0.321 & 0.001 & 0.002 & 0.124 \\
\hline
\end{tabular}

Notes: Data were presented based on mean \pm SD. Meaningful statistical significance was calculated using independent $t$-test.

Abbreviations: TG, triglyceride; LDL-c, LDL-cholesterol; HDL-c, HDL-cholesterol. 


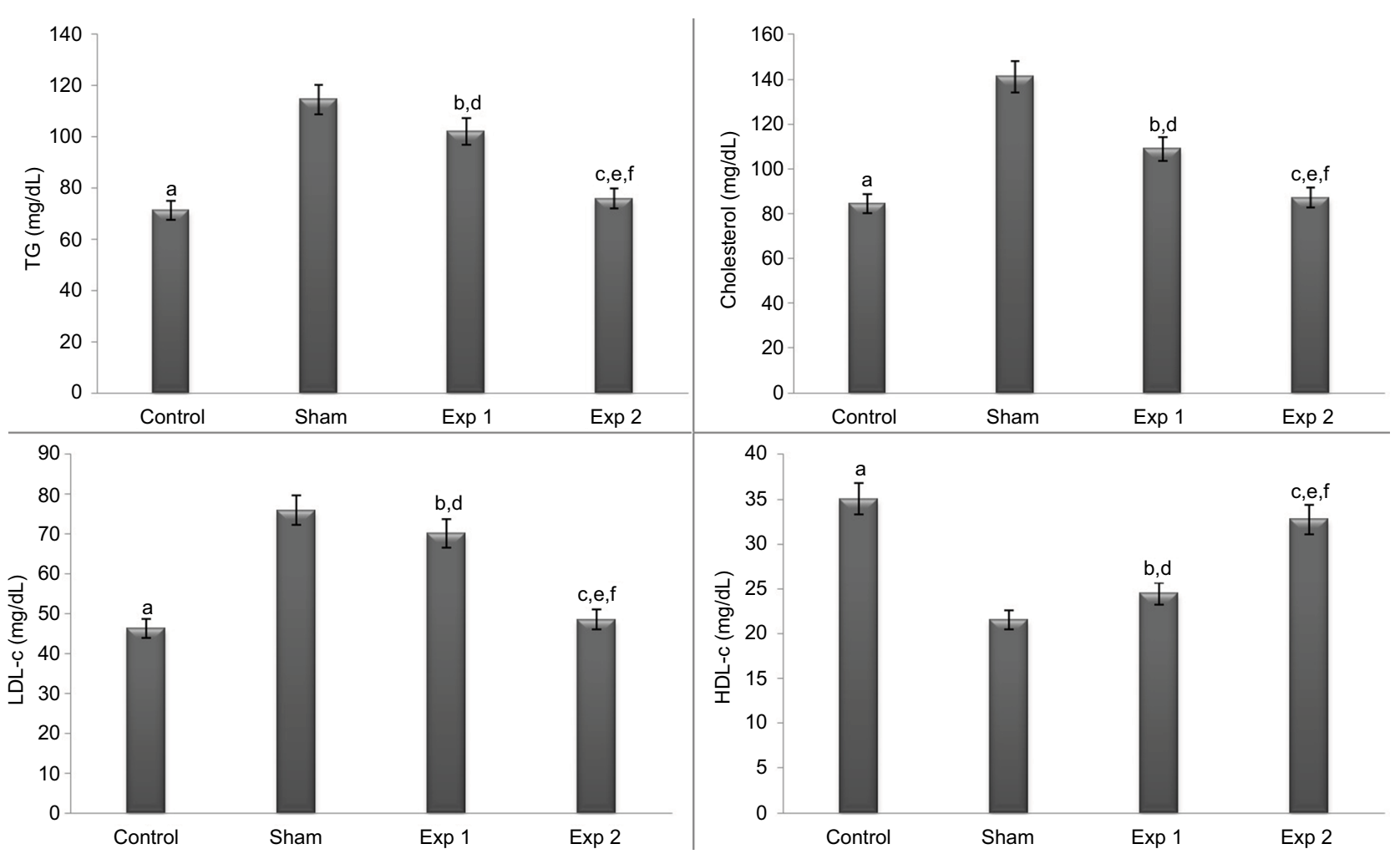

Figure I Effect of hydroalcoholic extracts of Teucrium polium on lipid profile (TG, cholesterol, LDL-c and HDL-c) in different groups.

Notes: The $P$-values for the following comparisons are as follows: end level serum of control vs. sham group ( $a=0.000)$; end level serum of Exp I vs. sham group (TG: $b=0.016$, cholesterol: $b=0.000$, LDL-c: $b=0.345$, HDL-c: $b=0.355$ ); end level serum of $\operatorname{Exp} 2$ vs. sham group ( $c=0.000$ ); end level serum of Exp I vs. control group ( $=0.000$ ); end level serum of Exp 2 vs. control group (TG: e=0.773, cholesterol: e=0.982, LDL-c: $e=0.967$, HDL-c: $e=0.622$ ) and end level serum of Exp 2 vs. Exp I group ( $f=0.000$ ). (The mean difference is significant at the 0.05 level).

Abbreviations: TG, triglyceride; LDL-c, LDL-cholesterol; HDL-c, HDL-cholesterol; Exp, experimental.

reduced serum TG, cholesterol and LDL-c levels and significantly increased serum HDL-c levels in treated rats compared with the sham group. The effects of hypolipidemia of hydroalcoholic extract of T. polium in the present study are consistent with previous studies. For example, Haraguchi et al studied the effects of aqueous extract of T. polium on serum cholesterol levels; after conducting the relevant experiments, it was concluded that the aqueous extract of T. polium can reduce total cholesterol levels in the animal model by $29-46 \% .{ }^{19}$ The study by Rasekh et al also found the anti-lipid profile of the aqueous extract of pea petiole in rats. ${ }^{20}$ Researchers have also investigated the hypolipidemia effect of $T$. polium in diabetic animals; their studies have proven that treatment with peppermint plant significantly reduces hyperlipidemia and reduces the hypolipidemia effect of this plant, TG levels and serum cholesterol in diabetic animals. Therefore, this product can possibly prevent complications caused by dyslipidemia in diabetic patients. ${ }^{16,21,22} \mathrm{~T}$. polium contains a wide range of active agents including alkaloids, glycosides, terpenoids, sterols, triterpenes and flavonoids. ${ }^{23,24}$ Some types of flavonoids may eliminate lipid synthesis and liver secretion. ${ }^{25}$
On the other hand, hypolipidemic and antioxidants compounds prevent progression of atherosclerosis and result in regression of this disease. ${ }^{26}$ Studies have shown that prevention of the development of atherosclerosis is associated with the reduction of oxidative stress. ${ }^{6}$ Oxidative stress is one of the important factors in increasing the production of RONs associated with hyperlipidemia. ${ }^{27,28}$ Hyperlipidemia results in inactivation of nitric oxide and ultimately endothelial damage in all stages of atherosclerosis by increasing the production of superoxide. ${ }^{29}$ Cardiovascular risk factors increase the oxidation of lipids, leading to normal vascular endothelial dysfunction and the formation of plaque atheroma. ${ }^{26}$ During the process of lipid peroxidation, there are several steps that result in the production of a wide range of substances, including free oxygen radicals, ketones, ethers, aldehydes and foam cells. These compounds interfere with the attachment of endothelial cells and formation of plaque. ${ }^{30}$

Other results of this study involved the investigation of the effect of $T$. polium on the levels of blood inflammatory factors. In clinical trials, it involved blood inflammatory factors including CRP, TNF- $\alpha$, IL- $\beta 1$ and IL- 6 along with the development of cardiovascular diseases, including coronary 


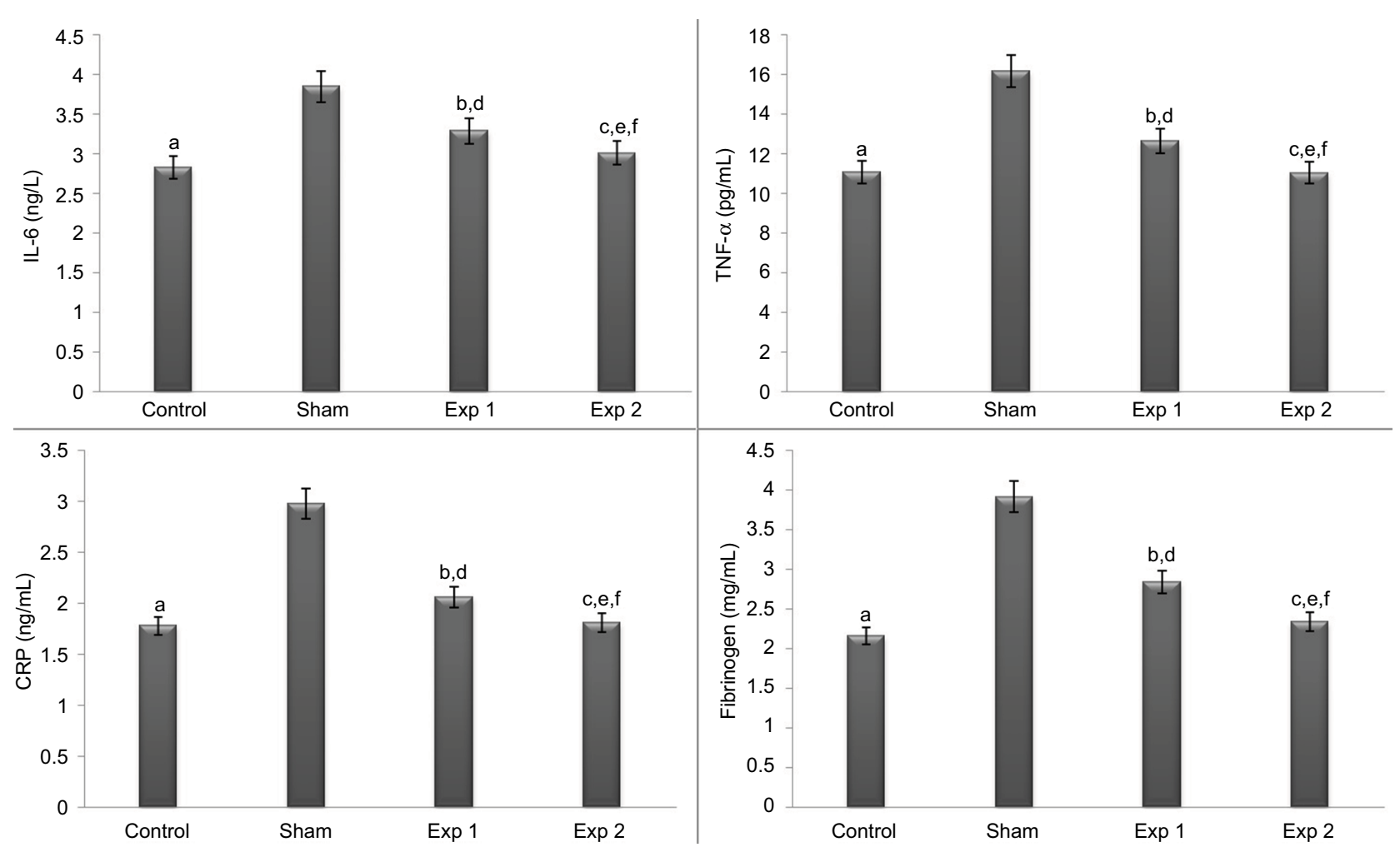

Figure 2 Effect of hydroalcoholic extracts of Teucrium polium on inflammatory indicators (IL-6, TNF- $\alpha$, CRP and fibrinogen) in different groups.

Notes: The $P$-values for the following comparisons are as follows: end level serum of control vs. sham group ( $a=0.000$ ); end level serum of Exp I vs. sham group ( $b=0.000$ ); end level serum of Exp 2 vs. sham group (c=0.000); end level serum of Exp I vs. control group (IL-6, TNF- $\alpha$ and fibrinogen: $d=0.000$, CRP: $d=0$. I 97 ); end level serum of Exp 2 vs. control group (IL-6: $e=0.198$, TNF- $\alpha$ and CRP: $e=1.000$, fibrinogen: $e=0.933$ ) and end level serum of Exp 2 vs. Exp I group (IL-6: $f=0.016$, TNF- $\alpha$ and fibrinogen: $f=0.000$, CRP: $f=0.296$ ). (The mean difference is significant at the 0.05 level.)

Abbreviations: TNF- $\alpha$, tumor necrosis factor- $\alpha$; Exp, experimental.

artery sclerosis. ${ }^{31,32}$ With increasing oxidative stress, inflammation increases, which is associated with an increase in the level of inflammatory factors. ${ }^{33}$ Some inflammatory factors, including CRP, have been elevated with an increase in cholesterol levels and are considered as important factors in predicting cardiovascular disease. ${ }^{34}$ The results of this study indicate that hydroalcoholic extract of blood has the potential to reduce inflammatory factors; administration of hydroalcoholic extract of $T$. polium causes a significant decrease in serum levels of IL- 6 , CRP, fibrinogen and TNF- $\alpha$. Similar to the results of this study, previous studies have reported that $T$. polium has antioxidant and anti-inflammatory activities. ${ }^{14,35}$ In a study investigating the anti-inflammatory activity of $T$. polium against edema caused by carrageenan in rats, it was shown that this herb has an anti-inflammatory effect. ${ }^{36}$ In another study by Radhakrishnan et al, it was concluded that topical use of T. polium extract had an antiinflammatory effect. ${ }^{37}$

Oxygen radicals play an essential role in development of atherosclerosis. ${ }^{38}$ Fats and proteins are damaged by free radicals, resulting in loss of integrity and pro-inflammatory cytokines. ${ }^{39}$
It seems that the antioxidant effect of the hydroalcoholic extract of T. polium is due to its flavonoid and phenolic compound content. Flavonoids protect the cells against the destructive effects of reactive oxygen species such as superoxide radicals because of their antioxidant activity. ${ }^{11}$ Flavonoids also reduce inflammatory processes by activating several pathways.$^{40}$ Compounds such as soluble fiber, vitamin E, flavonoids and sterols have anti-atherosclerotic effects, antioxidant and anti-inflammatory effects along with maintaining endothelial activity. ${ }^{41,42}$ Farshchi et al showed that the anti-inflammatory effects of aqueous extract of $T$. polium can be due to central and peripheral mechanisms, which are caused by the presence of alkaloids, flavonoids and terpenoids. ${ }^{43}$ In this study, doses of 85 and $170 \mathrm{mg} / \mathrm{kg}$ were used. From the results it was found that the protective effect was dose dependent, as shown in the dose of $170 \mathrm{mg} / \mathrm{kg}$. In the study conducted by Pourmotabbed et al, anti-inflammatory effects of the aqueous extract of T. polium were reported. ${ }^{36}$ In a study by Khleifat et al, the effects of long-term treatment of $T$. polium ethanolic extract on blood and biochemical, liver and kidney histopathology parameters in rats were investigated; this study revealed some of the phytotoxic effects of $T$. polium 
on the liver and kidneys through the long-term treatment. ${ }^{44}$ The findings of previous studies also reported acute hepatic failure in humans after use of chronic T. polium and its similar genus (Teucrium chamaedrys). ${ }^{45,46}$ In this study, the toxicity test $\left(\mathrm{LD}_{50}\right)$ was used to assess the toxicity of the drug, and the safety of the alcoholic extract of $T$. polium was confirmed in the applied doses. Other studies have also confirmed this result and have shown the safety of the studied extract. ${ }^{40,47}$ Therefore, it can be concluded that hydroalcoholic extract of T. polium is effective in reducing the level of inflammatory factors and lipid profiles in animal samples. However, further studies are needed in humans considering the confirmed phytotoxic effects of this plant in previous studies.

\section{Conclusion}

The results of this study showed that administration of hydroalcoholic extracts of T. polium in hypercholesterolemic rats significantly decreased serum levels of TG, cholesterol and LDL-c and significantly increased serum HDL-c levels. The extract also had the potential to reduce inflammatory factors, which resulted in a significant decrease in serum levels of IL-6, CRP, fibrinogen and TNF- $\alpha$ in hypercholesterolemic rats. The mechanism of this plant is likely to produce hypolipidemic and anti-inflammatory effects due to its polyphenolic compounds content. In addition, the results of the present study indicated that the protective effect of hydroalcoholic extract of T.polium was dose dependent as it was observed at a dose of $170 \mathrm{mg} / \mathrm{kg}$. It can be concluded that a dose of 170 $\mathrm{mg} / \mathrm{kg}$ of TPHAE has the potential to be a natural product to manage cardiovascular disease.

\section{Acknowledgment}

We would like to thank the Deputy Director of Research and Technology at Ilam University of Medical Sciences for supporting this study.

\section{Disclosure}

The authors report no conflicts of interest in this work.

\section{References}

1. Murphy SL, Kochanek KD, Xu J, Heron M. Deaths: final data for 2012. Natl Vital Stat Rep. 2015;63(9):1-117.

2. Benjamin EJ, Blaha MJ, Chiuve SE, et al; American Heart Association Statistics Committee and Stroke Statistics Subcommittee. Heart disease and stroke statistics-2017 update: a report from the American Heart Association. Circulation. 2017;135(10):e146-e603.

3. Pearson TA, Palaniappan LP, Artinian NT, et al; American Heart Association Council on Epidemiology and Prevention. American Heart Association Guide for Improving Cardiovascular Health at the Community Level, 2013 update: a scientific statement for public health practitioners, healthcare providers, and health policy makers. Circulation. 2013;127(16):1730-1753.
4. Pan LL, Qin M, Liu XH, Zhu YZ. The role of hydrogen sulfide on cardiovascular homeostasis: an overview with update on immunomodulation. Front Pharmacol. 2017;8:686.

5. Libby P, Hansson GK. Inflammation and immunity in diseases of the arterial tree: players and layers. Circ Res. 2015;116(2):307-311.

6. Kirbis S, Breskvar UD, Sabovic M, Zupan I, Sinkovic A. Inflammation markers in patients with coronary artery disease - comparison of intracoronary and systemic levels. Wien Klin Wochenschr. 2010;122(Suppl2): 31-34.

7. Moore KJ, Tabas I. Macrophages in the pathogenesis of atherosclerosis. Cell. 2011;145(3):341-355.

8. Faizal P, Acharya LD, Padmakumar R, Krathish B, Sureshwar P. Evaluation of risk factors and in-hospital outcomes in patients with coronary artery disease in a tertiary care teaching hospital. Int J Pharm Tech Res. 2009;1(4):1378-1386.

9. Hertog MG, Kromhout D, Aravanis C, et al. Flavonoid intake and longterm risk of coronary heart disease and cancer in the seven countries study. Arch Intern Med. 1995;155(4):381-386.

10. Parfitt VJ, Rubba P, Bolton C, Marotta G, Hartog M, Mancini M. A comparison of antioxidant status and free radical peroxidation of plasma lipoproteins in healthy young persons from Naples and Bristol. Eur Heart J. 1994;15(7):871-876.

11. Morel I, Lescoat G, Cogrel P, et al. Antioxidant and iron chelating activities of flavonoids of the catechin, quercetin and diosmetin on ironloaded rat hepatocyte cultures. Biochem Pharmacol. 1993;45(1):13-19.

12. Ricci D, Fraternale D, Giamperi L, et al. Chemical composition, antimicrobial and antioxidant activity of the essential oil of Teucrium marum (Lamiaceae). J Ethnopharmacol. 2005;98(1-2):195-200.

13. Abdollahi M, Karimpour H, Monsef-Esfehani HR. Antinociceptive effects of Teucrium polium L. total extract and essential oil in mouse writhing test. Pharmacol Res. 2003;48(1):31-35.

14. Ljubuncic P, Dakwar S, Portnaya I, Cogan U, Azaizeh H, Bomzon A. Aqueous extracts of Teucrium polium possess remarkable antioxidant activity in vitro. Evid Based Complement Alternat Med. 2006;3(3): 329-338.

15. Karimi F, Abbasi S, Bateni AR. The effect of Teucrium polium on blood glucose in diabetes mellitus type 2; a comparison with glibenclamide. Iran South Med J. 2002;4(2):96-103.

16. Suboh SM, Bilto YY, Aburjai TA. Protective effects of selected medicinal plants against protein degeneration, lipid peroxidation and deformability loss of oxidatively stressed human erythrocytes. Phytother Res. 2004;18(4):280-284.

17. Krause MP, Hallage T, Gama MP, et al. Associação entre Perfil lipídico e Adiposidade Corporal em mulheres com mais de 60 Anos de idade [Association between lipid profile and adiposity in women over age 60]. Arq Bras Cardiol. 2007;89(3):147-153. [Article in English and Portuguese].

18. Sarni RS, de Souza FI, Schoeps Dde O, et al. Relationship between waist circumference and nutritional status, lipid profile and blood pressure in low socioeconomic level pre-school children. Arq Bras Cardiol. 2006;87(2):153-158.

19. Haraguchi $\mathrm{H}$, Inoue J, Tamura Y, Mizutani K. Antioxidative components of Psoralea corylifolia (Leguminosae). Phytother Res. 2002;16(6):539-544.

20. Rasekh HR, Khoshnood-Mansourkhani MJ, Kamalianejad M. Hypolipidemic effects of Teucrium polium in rats. Fitoterapia. 2001;72(8): 937-939.

21. Shafiee-Nick R, Ghorbani A, Vafaee-Bagheri F, Rakhshandeh H. Chronic administration of a combination of six herbs inhibits the progression of hyperglycemia and decreases serum lipids and aspartate amino transferase activity in diabetic rats. Adv Pharmacol Sci. 2012;2012:789796.

22. Shahraki MR, Arab MR, Mirimokaddam E, Palan MJ. The effect of Teucrium polium (Calpoureh) on liver function, serum lipids and glucose in diabetic male rats. Iran Biomed J. 2007;11(1):65-68.

23. Kamel A. 7-Epi-eudesmanes from Teucrium polium. J Nat Prod. 1995; 58(3):428-431.

24. Rizk AM, Hammouda FM, Rimpler H, Kamel A. Iridois and flavonoids of Teucrium polium herb. Planta Med. 1989;52(2):87-88. 
25. Hii CS, Howell SL. Effect of flavonoids on insulin secretion and $45 \mathrm{Ca}^{2+}$ handling in rat islets of Langerhans. J Endocrinol. 1985;107(1):1-8.

26. Antman EM, Selwyn AD, Loscalzo J. Ischemic heart disease. In: Longo DL, Fauci AS, Kasper DL, Hauser SL, Jameson JL, Loscalzo J (Eds). Harrison's Principles of Internal Medicine, 18th edition. The McGrawHill Companies Inc: New York, NY; 2012:1998-2015.

27. Sies H, Stahl W, Sevanian A. Nutritional, dietary and postprandial oxidative stress. J Nutr. 2005;135(5):969-972.

28. O'Keefe JH, Bell DS. Postprandial hyperglycemia/hyperlipidemia (postprandial dysmetabolism) is a cardiovascular risk factor. Am J Cardiol. 2007;100(5):899-904.

29. Khansari N, Shakiba Y, Mahmoudi M. Chronic inflammation and oxidative stress as a major cause of age-related diseases and cancer. Recent Pat Inflamm Allergy Drug Discov. 2009;3(1):73-80.

30. Cushing SD, Berliner JA, Valente AJ, et al. Minimally modified low density lipoprotein induces monocyte chemotactic protein 1 in human endothelial cells and smooth muscle cells. Proc Natl Acad Sci U SA. 1990;87(13):5134-5138.

31. Baldassarre D, Porta B, Camera M, et al; MIAMI Study Group. Markers of inflammation, thrombosis and endothelial activation correlate with carotid IMT regression in stable coronary disease after atorvastatin treatment. Nutr Metab Cardiovasc Dis. 2009;19(7):481-490.

32. Pearson TA, Mensah GA, Alexander RW, et al; Centers for Disease Control and Prevention; American Heart Association. Markers of inflammation and cardiovascular disease: application to clinical and public health practice: a statement for healthcare professionals from the Centers for Disease Control and Prevention and the American Heart Association. Circulation. 2003;107(3):499-511.

33. Bell HK, Bloomer RJ. Impact of serum estradiol on postprandial lipemia, oxidative stress, and inflammation across a single menstrual cycle. Gend Med. 2010;7(2):166-178.

34. Murty D, Rajesh E, Raghava D, Raghavan TV, Surulivel MK. Hypolipidemic effect of arborium plus in experimentally induced hypercholestermic rabbits. Yakugaku Zasshi. 2010;130(6):841-846.

35. Tariq M, Ageel AM, al-Yahya MA, Mossa JS, al-Said MS. Anti-inflammatory activity of Teucrium polium. Int J Tissue React. 1989;11(4): $185-188$.
36. Pourmotabbed A, Farshchi A, Ghiasi G, Malek-Khatabi P. Analgesic and anti-inflammatory activity of Teucrium chamaedrys leaves aqueous extract in male rats. Iran J Basic Med Sci. 2010;13(3):119-125.

37. Radhakrishnan R, Zakaria MNM, Islam MW, et al. Analgesic and Anti-Inflammatory Activities of Teucrium stocksianum. J Pharm Biol. 2001;39(6):455-459.

38. Prasad K. A study on regression of hypercholesterolemic atherosclerosis in rabbits by flax lignan complex. J Cardiovasc Pharmacol Ther. 2007;12(4):304-313.

39. Cortese M, Sinclair C, Pulendran B. Translating glycolytic metabolism to innate immunity in dendritic cells. Cell Metab. 2014;19(5):737-739.

40. Houshmand Gh, Goudarzi M, Forouzandeh H, Nazari A, Nourollahi V. Evaluation of the analgesic effects of Teucrium extract on rats using the formalin test. J Babol Univ Med Sci. 2015;17(6):33-39.

41. Boban PT, Nambisan B, Sudhakaran PR. Dietary mucilage promotes regression of atheromatous lesions in hypercholesterolemic rabbits. Phytother Res. 2009;23(5):725-730.

42. Crujeiras AB, Parra MD, Rodriguez MC, Martinez de Morentin BE, Martinez JA. A role for fruit content in energy-restricted diets in improving antioxidant status in obese women during weight loss. Nutrition. 2006;22(6):593-599.

43. Farshchi A, Ghiasi G, Abdollahuasl A. Antinociceptive and antiinflammatory effects of Teucrium hyrcanicum aqueous extract in male mice and rats. Physiol Pharmacol. 2010;14(1):78-84.

44. Khleifat K, Shakhanbeh J, Tarawneh K. The chronic effects of Teucrium polium on some blood parameters and histopathology of liver and kidney in the rat. Turk J Biol. 2001;26:65-71.

45. Mattei A, Rucay P, Samuel D, Feray C, Reynes M, Bismuth H. Liver transplantation for severe acute liver failure after herbal medicine (Teucrium polium) administration. J Hepatol. 1995;22(5):597.

46. Larrey D, Vial T, Pauwels A, et al. Hepatitis after germander (Teucrium chamaedrys) administration: another instance of herbal medicine hepatotoxicity. Ann Intern Med. 1992;117(2):129-132.

47. Hasani P, Yasa N, Vosough-Ghanbari S, Mohammadirad A, Dehghan G, Abdollahi M. In vivo antioxidant potential of Teucrium polium, as compared to $\alpha$-tocopherol. Acta Pharm. 2007;57(1):123-129.
Journal of Inflammation Research

\section{Publish your work in this journal}

The Journal of Inflammation Research is an international, peer-reviewed open access journal that welcomes laboratory and clinical findings on the molecular basis, cell biology and pharmacology of inflammation including original research, reviews, symposium reports, hypothesis formation and commentaries on: acute/chronic inflammation; mediators of

\section{Dovepress}

inflammation; cellular processes; molecular mechanisms; pharmacology and novel anti-inflammatory drugs; clinical conditions involving inflammation. The manuscript management system is completely online and includes a very quick and fair peer-review system. Visit http://www.dove press.com/testimonials.php to read real quotes from published authors. 